\title{
Effect of water washing on oxalic acid content of various fodders and its determination
}

\author{
A Kumar, CS Barsaul \\ Dept of Animal Nutrition and Feed Technology, College of Veterinary Science, CS Azad, \\ Agricultural University, Mathura (UP), India
}

\begin{abstract}
It has been reported that when certain fodders like Bajra stover (Pennisetum typhoides), Setaria grass (Setaria Aphocelata), Napier grass (Pennisetum Purpureum) and MP Chari (Sorghum bicolor) etc., were fed to dairy cows, their milk yield decreased. Analysis of these fodders reveals that high oxalic acid content, producing oxalate toxicity and interfering with the calcium metabolism, reduces milk yield. If these fodders are washed with water, soluble oxalates are released up to a safe limit (below $0.8 \%$ ) for animal consumption.
\end{abstract}

Oxalic acid content of fodders was determined according to the method of Talapatra et al (1948, Inc J Vet Sci and AH, 18, 99). During analysis it was noted that leaves contain a higher percentage of oxalic acid than stem and whole plant. Similar results were also obtained by Anjum (1984, MV Sc Thesis). Furthermore, the content was higher in the earlier stages of growth than in the latter stages.
Fodders were washed with clean water, by soaking the cut fodder in large buckets for approximately half, and one and a half hours, respectively. Washed fodders were again analyzed for their oxalic acid content. The results of both analyses are shown in the table below.

It is quite clear that one and a half hours of soaking in water removes more soluble oxalates from the fodders, as compared with half an hour. Consequently, farmers were advised that fodders with high oxalic acid content may be fed to dairy cows, after soaking and washing with water. Farmers have since reported significant increases in milk yields.

Therefore, water washing of oxalate rich fodders is recommended to farmers engaged in the dairy industry. A detailed project is under consideration on this subject.

$\begin{array}{lccc}\text { Name of fodders } & \begin{array}{c}\text { Oxalic acid } \\ (\%)\end{array} & \begin{array}{c}\text { Oxalic acid after } 1 / 2 \mathrm{~h} \\ \text { washing }(\%)\end{array} & \begin{array}{c}\text { Oxalic acid after } 11 / 2 \mathrm{~h} \\ \text { washing }(\%)\end{array} \\ \text { Bajra Stover } & 1.75 & 1.02 & 0.60 \\ \text { Setaria grass } & 1.55 & 0.82 & 0.45 \\ \text { Napier grass } & 1.60 & 1.20 & 0.71 \\ \text { MP Chari } & 0.45 & \text { Not needed } & \text { Not needed }\end{array}$

